\title{
Speech-Language Pathology Students' Perceptions of an IPE Stroke Workshop: A One-Year Follow up
}

\section{Sarah E. Wallace}

Duquesne University, sarah.wallace@pitt.edu

DOI: doi.org/10.30707/TLCSD1.1Wallace

Follow this and additional works at: https://ir.library.illinoisstate.edu/tlcsd

Part of the Scholarship of Teaching and Learning Commons, and the Speech Pathology and Audiology Commons

\section{Recommended Citation}

Wallace, Sarah E. (2017) "Speech-Language Pathology Students' Perceptions of an IPE Stroke Workshop: A One-Year Follow up," Teaching and Learning in Communication Sciences \& Disorders: Vol. 1: Iss. 1, Article 4.

DOI: doi.org/10.30707/TLCSD1.1Wallace

Available at: https://ir.library.illinoisstate.edu/tlcsd/vol1/iss1/4

This Scholarship of Teaching and Learning Research is brought to you for free and open access by ISU ReD: Research and eData. It has been accepted for inclusion in Teaching and Learning in Communication Sciences \& Disorders by an authorized editor of ISU ReD: Research and eData. For more information, please contact ISUReD@ilstu.edu. 


\title{
Speech-Language Pathology Students' Perceptions of an IPE Stroke Workshop: A One-Year Follow up
}

\author{
Abstract \\ Interprofessional education (IPE) activities are increasingly included in speech-language pathology (SLP) \\ curriculum; however, little is known about IPE's impact on students' clinical experiences. Additionally, few \\ studies have examined students' perceptions of IPE Competency Domains across a program of study or \\ within specific IPE activities. For this initial study, qualitative and quantitative analyses of 24 SLP \\ students' survey responses one year after an IPE Stroke Workshop highlighted the value of IPE. Students \\ emphasized the importance of hands on and real life activities as part of interprofessional learning. \\ Additionally, their responses suggest that multiple IPE Competency Domains may be addressed within a \\ single IPE activity; however, students' misconceptions of IPE may limit their report of IPE Competency \\ Domains covered. These findings provide insight to assist with integration of IPE to meet the needs of \\ SLP students.

\section{Keywords} \\ Interprofessional Education, IPE Domains, Follow up Perceptions of IPE

\section{Cover Page Footnote} \\ Acknowledgments: The author would like to thank the following student research assistants who helped \\ with the data collection and analysis: Sarah Diehl, Mary (Nellie) Flynn, and Lauren Adler. Additionally, the \\ author thanks her colleagues from the schools of Health Sciences, Nursing, and Pharmacy who assisted \\ with the planning and implementation of the Interprofessional Education Stroke Workshop. Finally, the \\ author would like to acknowledge the contributions of the patient and his family who helped make this \\ workshop a success.
}




\section{Introduction}

Interprofessional education (IPE) involves two or more professionals learning with, from, and about one another in academic and clinical practice settings (World Health Organization, 2010). IPE activities are designed to help students improve their understanding of and ability to work with different health professionals as described in the IPE Core Competencies (Interprofessional Education Collaborative Panel, 2011). The four IPE Core Competency Domains include: (1) values and ethics for interprofessional practice; (2) health professionals' roles and responsibilities; (3) interprofessional communication; and (4) teams and teamwork.

\section{Follow up Investigations of IPE}

Because the aim of IPE is to best prepare students for clinical practice, evaluation of the effect of IPE on clinical experiences is needed. However, of the many IPE reports that examined students' perceptions of IPE activities, only a few have provided specific information about studies' perceptions following at least one year of clinical experience.

Reeves and Freeth (2002) reported follow up data collected via questionnaire one year after students completed a pilot interprofessional training clinical practice project for medical, nursing, occupational therapy, and physiotherapy students. The follow up responses from 50\% of the student participants indicated that they thought the experience provided insight into the role of other professionals and the interprofessional team process. At follow up, the students also suggested improvements such as a longer placement, consistent facilitation of teams, and pretraining to reduce preconceived ideas about roles. Similarly, Hylin, Nyholm, Mattiasson, and Ponzer (2007) examined follow up data two years after students completed a two-week interprofessional clinical practicum focused on learning other professionals' roles and the importance of team communication. The questionnaire responses from $55 \%$ of the students (i.e., nursing, medical, physiotherapy, and occupational therapy students) highlighted the need for IPE and students' desire for additional opportunities. In addition, participants stated a need for IPE to take place early in academic programs and that skilled facilitators are needed to guide these activities. The general positive follow up comments from students at least one year post IPE activity, emphasized the value of these educational experiences. However, both of these activities involved clinical practicum IPE experiences, which currently may not be feasible for all educational programs who will opt to implement classroom or academic IPE activities. In addition to the limited number of studies that have examined follow up perceptions, few, if any studies, have asked students to reflect on the relative value of the four IPE Competency Domains. Understanding students' perceptions of their learning 
outcomes relative to the Competency Domains will assist educators in creating curriculum changes as new accreditation standards are implemented across multiple disciplines.

\section{IPE for Speech-Language Pathology Students}

Investigations of IPE often involve a mix of disciplines, occasionally with speechlanguage pathology (SLP) students as participants (e.g., Copley, Allison, Hill, Moran, Tait, \& Day, 2007; DiVall, Kolbog, Carney, Kirwin, Letzeiser \& Mohammaed, 2014; Edwards, Newell, Rich, \& Hitchcock, 2015; Kent, Drysdale, Martin, \& Keating. 2014; Nisbet, Hendry, Rolls, \& Fields, 2008; Pechak, Gonzalez, Summers, \& Capshaw. 2013; van Soeren, Delvin-Cop, MacMillan, Baker, EganLee, \& Reeves, 2011). A shift has occurred in the education of speech-language pathologists such that the Council on Academic Accreditation (CAA) (2016) now includes interprofessional education within multiple accreditation standards for graduate programs in SLP. These changes include requiring opportunities for students to: (a) demonstrate understanding with collaborative practice skills needed to work within an interprofessional team, (b) communicate with members of an interprofessional team, (c) apply shared values within an interprofessional team, and (d) understand the roles of interprofessional team members to increase the quality of assessment and intervention services. As these changes begin to occur in programs, educators will benefit from additional evidence about learning outcomes and experiences with IPE specific to SLP students.

Zhao, Nagarajan, and Nisbet (2015) provide one such examination of SLP student experiences through interviews with nine students in the final years of their undergraduate degree programs at an Australian university. This qualitative examination found that students described valuing the interprofessional learning experiences that often occurred informally during clinical placements. Although the results provide valuable insights, less is known about students' perceptions of IPE experiences resulting from completion of the curriculum in a CAA accredited graduate SLP program. With the changes in accreditation, educators will need to gain understanding in how students view formal and informal IPE activities implemented throughout the curriculum. Evaluating current programs, prior to implementation of activities to address the CAA accreditation standard may provide insight into future curriculum needs.

While Zhao and colleagues (2015) examined students' perceptions of formal and information interprofessional learning throughout an SLP program, most IPE investigations have focused on learning outcomes from a single experience. For example, Miolo and DeVore (2016) described students' experiences following an interprofessional collaborative practice experience with SLP and education 
students. Most of the students reported positive experiences and beneficial outcomes for the children receiving services. A similar investigation sought to identify students' perceptions following an interprofessional clinical education experience for SLP and clinical psychology students (Coiro, Kotchick, \& Preis, 2016). Despite differences in the interprofessional activities and research methods across studies, the findings from the studies described above suggest that SLP students perceive achieving learning outcomes that can be tied back the IPE competencies (Coiro, et al., 2016; Miolo \& DeVore, 2016; Zhao et al., 2015). The recent examinations of perceptions SLP students following interprofessional learning activities provide meaningful evidence for the development of future IPE activities. However, additional evidence is needed to understand the effect of IPE activities on future clinical experience with a particular focus on the experience of SLP students.

Therefore, the purpose of the current study was to examine SLP students' perceptions of an IPE Stroke Workshop after one year of clinical practicum experiences. That is, the researcher sought to describe students' perceptions of a previous IPE activity after they had an additional year of clinical experience. Second, the researcher sought to examine students' perceptions IPE Competency Domains across the curriculum prior to the implementation of CAA standards and their perceptions of IPE Stroke Workshop learning outcomes specifically related to the IPE Competency Domains.

\section{Methods}

\section{Participants}

Participants included 24 SLP graduate students. One year prior to participating in the current study aimed at measuring their follow up perceptions, all students completed an IPE Stroke Workshop with students from seven other health care disciplines (i.e., physical therapy, athletic training, health management systems, nursing, occupational therapy, physical assistant studies, and pharmacy). Students completed the study procedures and the IPE Stroke Workshop as part of a course requirement; however, they were not required to provide permission for their data to be analyzed for the current study. All students completed consent forms approved by the University's institutional review board indicating their data could be used for research purposes.

Since the time of the workshop, the students had completed one semester of clinical practicum in an outpatient university clinic and one and a half semesters (i.e., approximately 20 weeks total) of clinical practicum external to the university clinic. The researcher collected further information about the type of clinical practicum experiences via questionnaire. This data is available in the Results section. 


\section{Materials}

Students completed a follow up questionnaire (Appendix) designed to capture information about their clinical experiences with stroke and their perceptions of the IPE Stroke Workshop. Students completed the questionnaire one year after their completion of the IPE Stroke Workshop. The questionnaire first asked students to report their hours and types of clinical experiences since the time of the workshop. Second, students were asked to select the elements of the IPE Stroke Workshop that were most and least valuable for their future clinical experiences. Then, the questionnaire provided information about the four IPE Competency Domains and asked students to describe which of Competency Domains was most and least valuable for future clinical practice, as well as comment on their perceptions of inclusion of any of the Competency Domains in their academic course work and the IPE Stroke Workshop. Finally, the questionnaire included two open-ended questions about the effect of the workshop on the way students viewed other healthcare professions and a description of the most valuable aspect of the workshop. The questionnaire also included a space for students to provide additional comments.

Artifacts were collected related to the courses offered in the students' regular curriculum. Specifically, the researcher reviewed a list of courses and instructorcreated course descriptions from the university website.

\section{IPE Stroke Workshop}

Students completed an IPE Stroke Workshop one year prior to the current study. A complete description of the workshop is available in Wallace and colleagues (2016). The multi-stage IPE Stroke Workshop was a three-hour event designed by faculty members from the schools of Health Sciences, Nursing, and Pharmacy to provide students with an interprofessional learning experience related to healthcare discipline roles in stroke care and general content about stroke. Workshop participants included 14 athletic training students, 18 health management systems students, 27 occupational therapy students, 51 physician assistant studies students, 82 nursing students, and 159 pharmacy students. Students participated in one of three identical workshops, which included small and large group activities. The faculty assigned students to small interprofessional groups of 12 to 15 students each with representatives from most of the eight disciplines.

Prior to attending the workshop, students reviewed a patient biography and online videos on the topics of collaboration and stroke. During the workshop, students were introduced to a 40-year old patient who was 10 years post-left hemisphere infarct. As a result of his stroke, the patient was diagnosed with Broca's aphasia, apraxia of speech, right hemiparesis in the upper and lower extremities, and right 
homonymous hemianopia. After patient, family, and faculty introductions, the students divided into the 10 assigned, small interprofessional groups to identify areas of concern and develop patient questions. Students returned as a large group to ask the patient, his parents, and his siblings questions about the identified areas of concern. The students divided into their small interprofessional groups to develop a plan of care based on patient and family responses. Finally, the students returned to the large group to share information about the plan of care and reflect on the workshop experience.

\section{Study Procedures}

One year following the workshop, the students logged onto a course website to submit responses to the questionnaire (described above) within a word document that was uploaded to the site. Students had one month to complete their responses to the questionnaire and received three reminders via the course website. All 24 eligible participants completed the study procedures and gave permission for their data to be analyzed. A research assistant deidentified the responses and organized them within a single transcript.

\section{Data Analysis}

The researcher used Microsoft Excel@ $\subseteq$ to calculate means, standard deviations, and ranges for students' self-reported data about their clinical experiences during the one year after the IPE Stroke Workshop. The researcher also tabulated the responses to questions related to the four IPE Competency Domains covered across the SLP curriculum and within the IPE Stroke Workshop.

The researcher and two student research assistants analyzed the responses to openended question transcripts using various systematic steps recommended by Moustakas (1994) for phenomenological research. They progressed from narrow units of analysis to broader units, and later created detailed summarized descriptions. First, the research team members read the typed transcripts to obtain an overall impression of the participants' responses. Subsequent steps included open coding, horizontalization of participant statements, creation of meaning units, and organization of related codes. Open coding consisted of labeling statements relating to the study purpose. Horizontalization required the researchers to consider each response with equal weight, leading to the development of meaning units. Then, the researchers considered overlapping meaning units and organized related meaning units into categories, themes, and subthemes (Creswell, 2013; Merriam, 2009; Moustakas, 1994). 
Three research team members independently analyzed transcripts using Moustakas' procedures and compared themes across those transcripts as a means of evaluating intercoder consistency. Two research team members coded half of the transcripts each and the third researcher (first author) coded all transcripts. Differences in identified codes were discussed until the research team members reached consensus. Then, the research team members analyzed and coded the remaining transcripts. The researchers were careful to ensure that their personal beliefs and professional biases did not influence their data interpretation. This was particularly important because the first author was involved in the IPE Stroke Workshop, and provided clinical and academic content on the topic of stroke (Creswell, 2013; Merriam, 2009).

The research team members used two types of verification procedures to establish validity of results: (a) triangulation and (b) searching for disconfirming evidence. For triangulation, researchers sought to identify consistent themes among various sources (24 participants with different clinical experiences) and compare students' responses to artifacts (e.g., course descriptions available via the university website). Next, the research team members examined transcripts for disconfirming evidence of themes. Themes identified by the researchers were generally consistent across most of the 24 participants; however, some individual differences were noted likely due to the differences in participants' clinical experiences, practicum settings, and clinical interests.

\section{Results}

\section{Student Clinical Experience}

Students reported information about the numbers of hours and types of clinical practicums they participated in during the one-year following the IPE Stroke Workshop. Students reported experience in the following external clinical practicums settings: $8(33.33 \%)$ in a medical outpatient practicum, $2(8.33 \%)$ in a pediatric outpatient practicum, $14(58.33 \%)$ in an adult inpatient practicum, 1 in a pediatric inpatient practicum, $10(41.67 \%)$ in a skilled nursing facility, $14(58.33 \%)$ in a school setting, and $10(41.67 \%)$ in a special school setting. Students may have had practicum experiences in various settings during a single semester because of multi-setting placements (e.g., hospital placements wherein students provide inpatient and outpatient therapy). Regarding populations served, 22 (91.67\%) of students reported working with elderly adults and 17 (70.83\%) reported working with adults during the year following the IPE Stroke Workshop. On average, students reported providing clinical services to elderly adults for about 17.71 hours per week and to adults for about 9.71 hours per week. 
Of particular interest to the current study, students reported providing clinical services to people with stroke following the IPE Stroke Workshop an average of 126.83 total hours (SD $=135.80$ hours; Range $=5-400$ hours). Students reported that time spent providing services to individuals with stroke comprised 5\% to $75 \%$ $(\mathrm{M}=34.69 \% ; \mathrm{SD}=18.52 \%)$ of their total clinical experiences following the Stroke IPE Workshop.

\section{Students' Perceptions of IPE}

Two categories of themes emerged from the data analysis: (a) Perspective of the IPE Workshop and (b) Integration of IPE Competency Domains. Each category includes two to three themes and multiple subthemes.

Perspectives of the IPE Workshop included three themes: Increased Understanding, Valuable Aspects of the Workshop, and Recommendations for Future Workshops. Each theme included multiple subthemes that highlight the most frequent responses by students. The framework for the first category of themes is shown in Figure 1 with relevant quotations from participants.

The second category of themes, Integration of IPE Competency Domains, included two themes: IPE Domains in General Curriculum and IPE Domains Perceived Importance for Future Clinical Work. These responses highlight where and when students perceived learning information related to the IPE Competency Domains. Additionally, students frequently provided information about the relative value of particular themes in their clinical practice. Figure 2 shows this second category of themes and example quotations from participants. 
Teaching and Learning in Communication Sciences \& Disorders, Vol. 1 [2017], Iss. 1, Art. 4

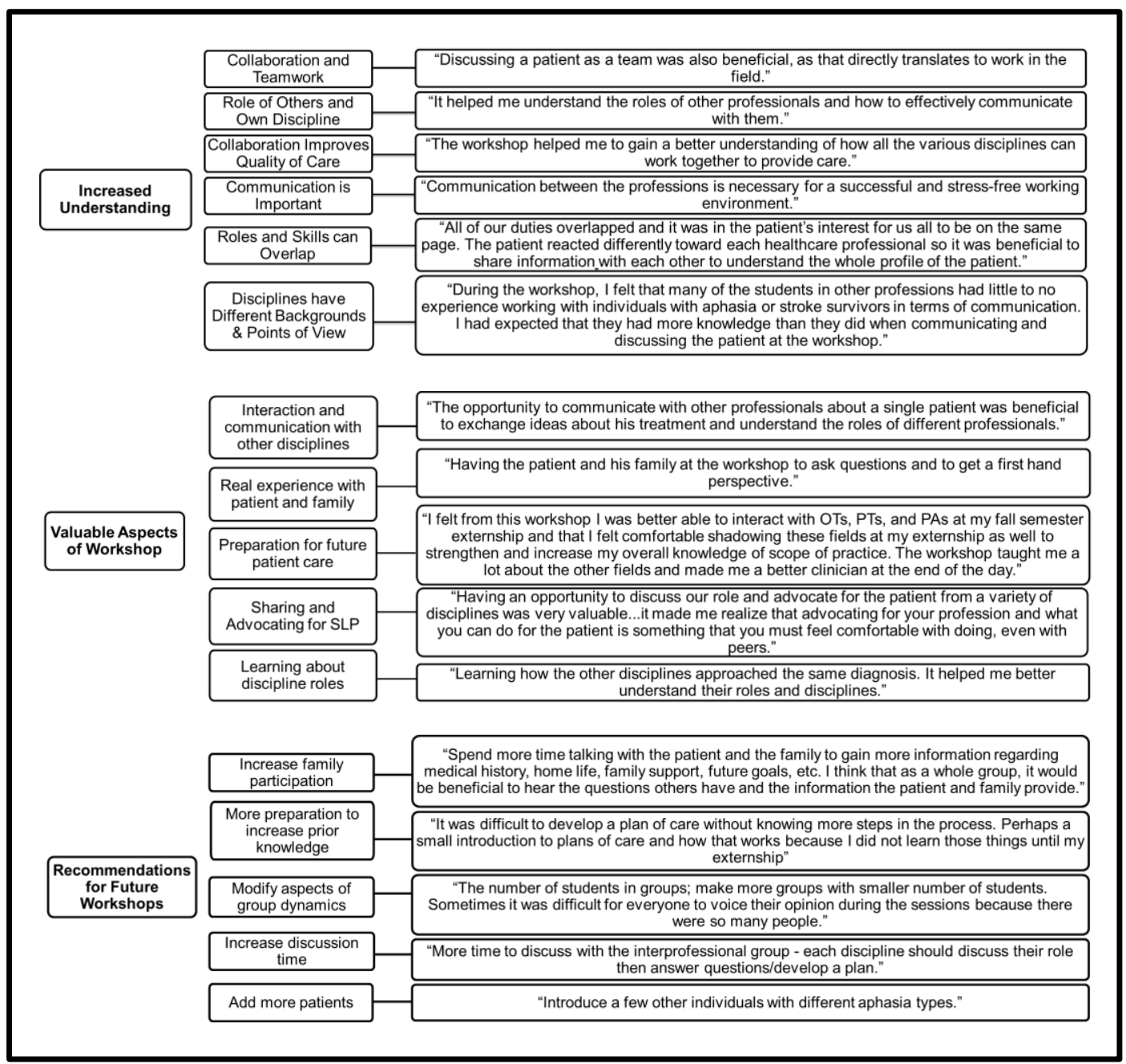

\section{Figure 1. Theme Category 1: Perspectives of IPE Workshop}




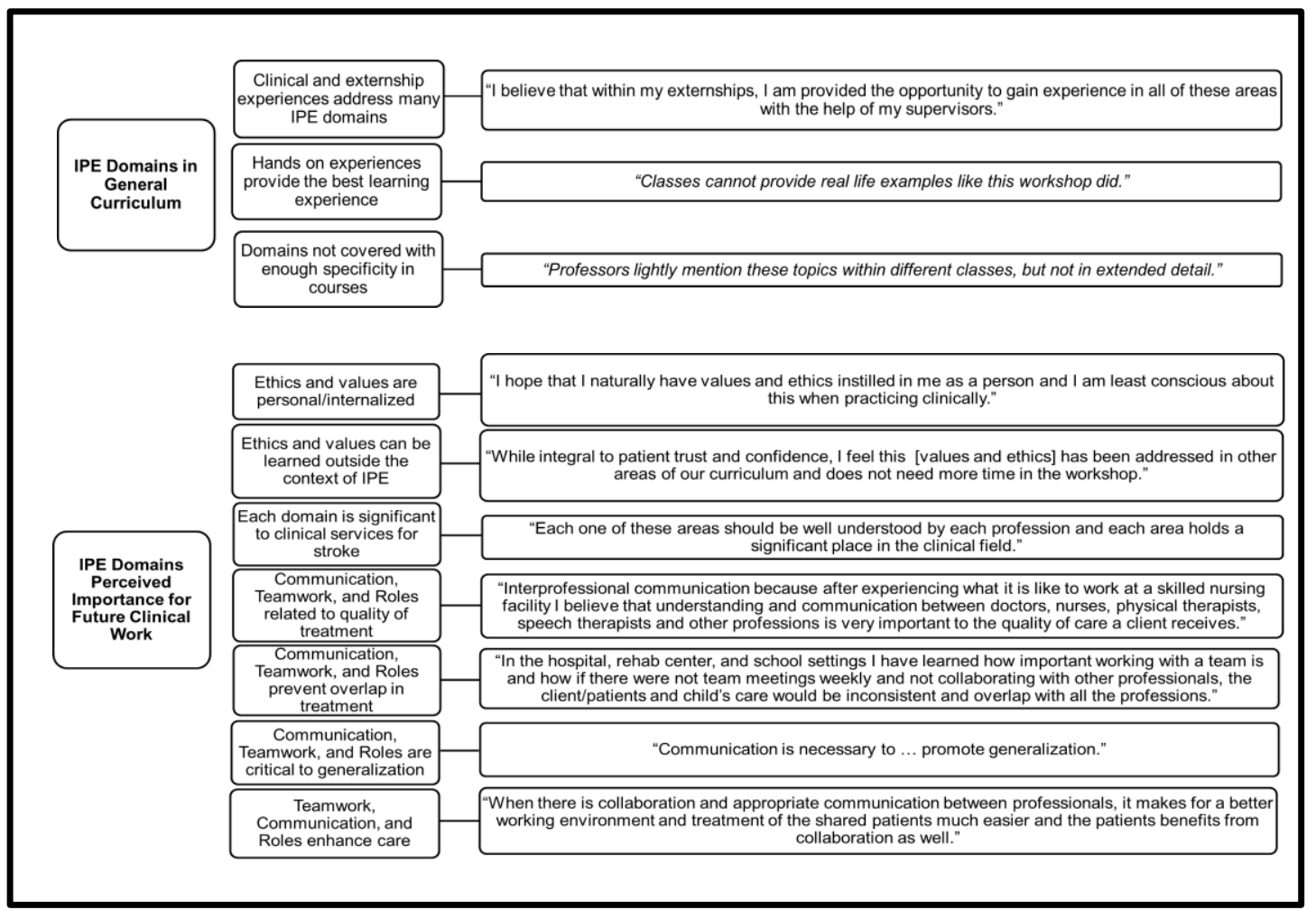

Figure 2. Theme Category 2: Integration of IPE Competency Domains

\section{IPE within the SLP Curriculum}

Similar to the information within the second category of themes, participants also provided quantitative data related to their perceptions about when, where, and how IPE Competency Domains were addressed (See Figure 3). For example, six of the 24 participants reported learning about the IPE Competency Domains of Interprofessional Communication, and Teams and Teamwork in their Medical Speech-Language Pathology Course, and fewer students reported covering these same Competency Domains in other courses. Four students felt that these two Competency Domains were covered in all or most of the courses. Eight students felt that all or most of the courses provided information about the IPE Competency Domain Roles and Responsibilities. Finally, 17 students reported the Values and Ethics Domain was covered in their discipline-specific ethics course. The numbers represent the number of students that listed each course. None of the artifacts (i.e., course descriptions via university website) provided information about the integration of any IPE Competency Domains. 


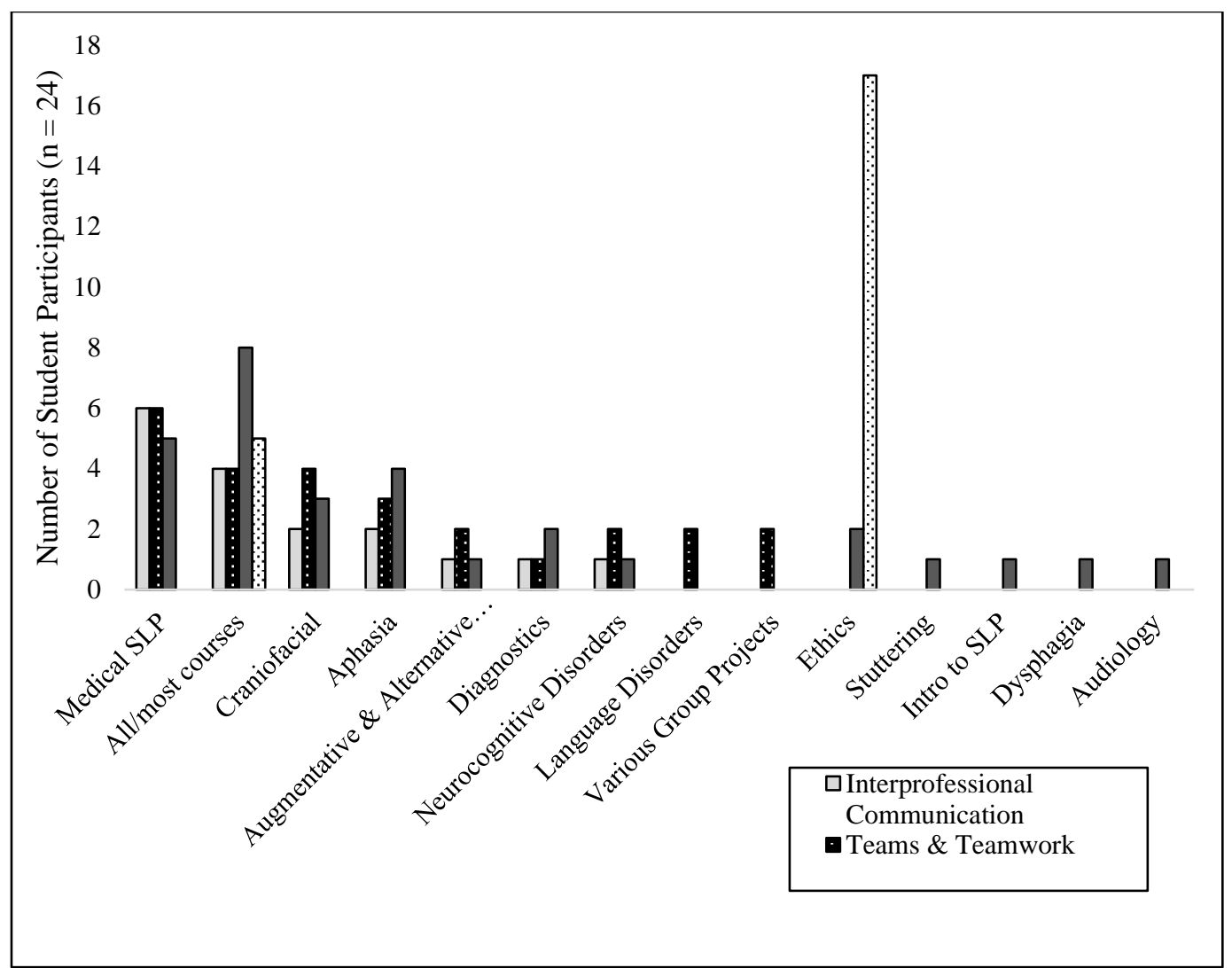

Figure 3. Students' Report of Courses that Address IPE Competency Domains Across the Curriculum

Students also reported the absence of specific IPE Competency Domains from their curriculum. For example, Interprofessional Communication was most frequently ( 5 students) reported as not being covered in the curriculum. Fewer students reported Roles and Responsibilities, Teams and Teamwork, as well as Values and Ethics as not being covered in the general curriculum (3,2, and 1 student respectively).

Finally, the students were asked to report which of the IPE Competency Domains were addressed in the IPE Stroke Workshop (See Figure 4). Fourteen students reported that both Interprofessional Communication, and Teams and Teamwork were covered in the workshop. Additionally, eight students believed the Roles and Responsibilities were addressed in the workshop, while another eight students reported that all Competency Domains were covered in the workshop. 


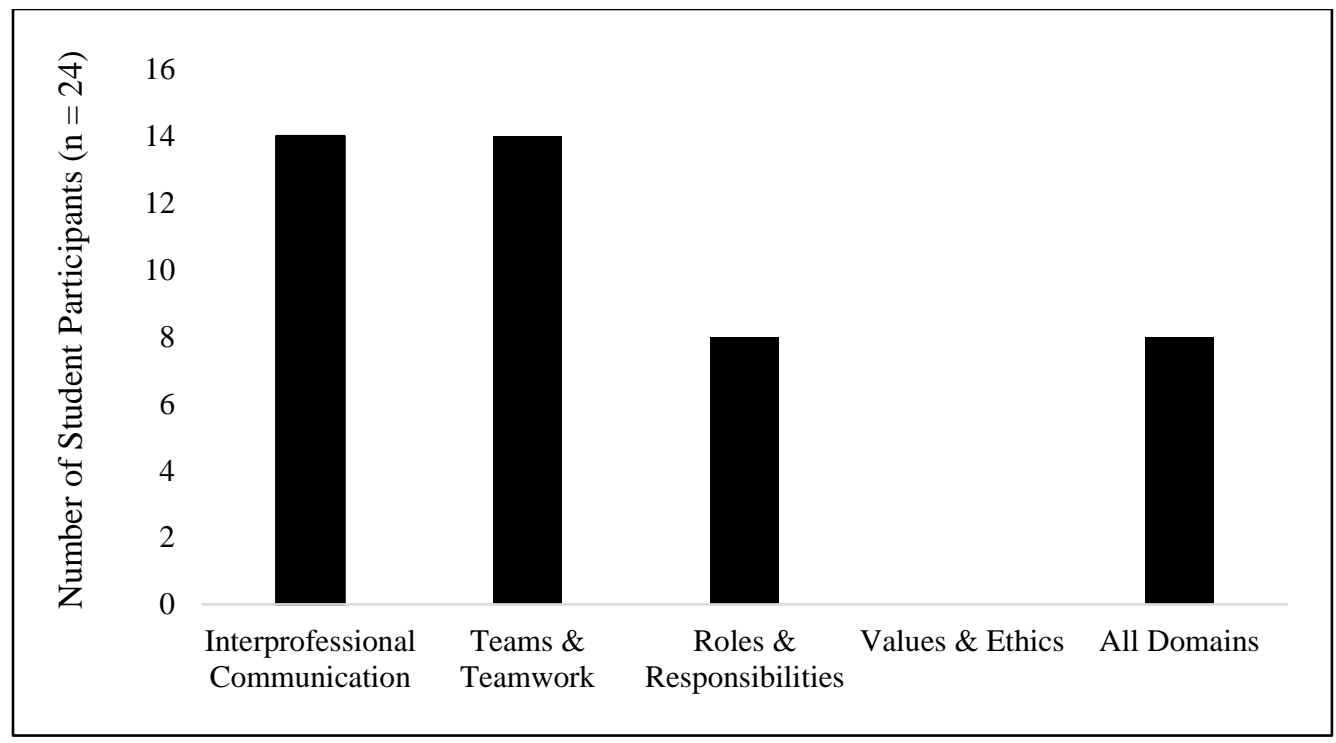

Figure 4. IPE Competency Domains Students Report as Covered during the Stroke IPE Workshop

\section{Discussion}

\section{Benefits of IPE}

Although exploratory in nature, the current study provides valuable insights into students' perceptions of IPE after one year of clinical externship experiences. Students generally reported finding multiple connections between their learning during the Stroke IPE Workshop and their future clinical practice. Specifically, they described how the workshop helped them learn about appropriate communication strategies for working with other healthcare professionals and increased understanding of each discipline's role. Reeves and Freeth (2002) also found in a one-year follow up study that students reported greater insight into other disciplines' roles and increased understanding of teamwork. These findings suggest that various aspects of the workshop were relevant to students' future clinical experience such as the patient and family interaction, as well as the experience of advocating for their discipline's role. These results are consistent with research that suggests changes in students' perceptions occur after IPE activities (Barnes, Carpenter, \& Dickinson, 2000; Evans, Henderson, \& Johnson, 2012; Neville, Petro, Mitchell, \& Brady, 2013).

The IPE Stroke Workshop was a single academic event that did not involve direct clinical interaction; however, the students' reported changes in their clinical skills 
similar to outcomes reported in follow up studies that have examined IPE clinical education activities (e.g., Hylin, et al., 2007; Reeves \& Freeth, 2002). Although further investigation is needed, the use of a single, real patient during academic IPE activities may reduce the burden on academic programs if they provide similar learning outcomes as IPE clinical educational experiences. That is, large group activities like the IPE Stroke Workshop may be an appropriate educational activity to provide students with as an adjunct to IPE clinical experiences, which may be challenging for a program to arrange for multiple students across each cohort. SLP students were notably absent in the above studies; therefore, the current findings represent an expansion of the evidence base for IPE.

\section{Learning within IPE Competency Domains}

The IPE Stroke Workshop examined within the current study aimed to cover learning related to the IPE Competency Domain Roles and Responsibilities; however, students reported learning across multiple Competency Domains. These findings suggest that IPE activities may indirectly target multiple IPE Competency Domains increasing the scope of each activity. Expansion of learning objectives from a single IPE activity is important for educators who already have limited time to teach discipline-specific content. In particular, this workshop covered content related to stroke and IPE allowing educators to combine learning objectives and not take time away from other critical content (Wallace et al., 2016). Future research may expand these results to consider how other IPE Competency Domains are addressed and which specific learning outcomes are achieved.

Many students felt the IPE Stroke Workshop covered multiple IPE Competency Domains. They reported less learning related to IPE within the general curriculum than from the workshop. This difference is to be expected, as the students were enrolled in a program that had not yet implemented multiple strategies for addressing IPE Competency Domains and the program faculty had not yet been trained in IPE instruction. Given these limitations, the number of IPE Competency Domains addressed in the general curriculum exceeded the researchers' expectations. These findings and the report of Competency Domains addressed within the workshop likely relate to a common misconception or poor understanding of IPE. Although student participants were provided with multiple definitions of IPE at the time of the workshop and the follow up questionnaire, it is possible that they indicated coverage of an IPE Competency Domain whenever something related to that Competency Domain (not necessarily as IPE) was covered in the general curriculum. For example, over half of the students $(n=17)$ indicated their Ethics course covered the IPE Competency Domain Values and Ethics. However, the instructor-created course descriptions did not specifically cover any content related to other disciplines or include IPE as part of the course. Based on a 
review of course descriptions, it is more likely that courses such as Medical SLP, Craniofacial, and Augmentative and Alternative Communication (identified from available course descriptions) covered content related to the IPE Competency Domains than all of those listed by students. Even within these courses, the students accurately reported that IPE concepts are covered only broadly and not addressed in detail.

As this curriculum is modified to meet the accreditation standards, more courses will likely cover IPE Competency Domains and students may gain an accurate definition of IPE. Given the challenges with implementing IPE (Reeves et al., 2010), the curriculum will likely include both real client interactions, like within the IPE Stroke Workshop, and simulated class activities. It is clear that students value the hands on experience provided by the IPE Stroke Workshop so as appropriate, these activities will be developed and included. Additionally, clinical IPE activities and informal activities (Zhao et al., 2015) may be developed to address learning related to some of the IPE Competency Domains. Follow up data is needed to confirm the value when programs integrate multiple formal and information IPE activities.

\section{Limitations and Future Research}

The present findings are limited in scope because they only included the SLP students and exclude seven other health professional disciplines who participated in the IPE Stroke Workshop. Furthermore, the small sample size of 24 students from one program of students limits the generalization of these results to other SLP programs and curriculums. The researcher was a faculty member facilitator for the workshop, which may have introduced some bias during analysis (although two research assistants verified the results). Given the follow up nature of the current study, students' perceptions of content covered in their courses and the IPE Stroke Workshop may have been changed by the passage of time and their varied clinical experiences. Additionally, the results of this study represented students' perceptions after just one year of additional clinical education experience. Future research should examine the perceived effect of IPE activities after a longer period of clinical practice across varied settings.

As curriculum changes occur across programs now required to address IPE-related outcomes, examination of immediate and long-term learning outcomes will provide educators with much needed information regarding the techniques that work best to help students achieve these objectives. Research is needed to determine the best ways in which to measure follow up experiences of students who complete IPE activities. Additionally, future research should examine the differences and similarities in the follow up responses from students associated with various 
disciplines. Finally, researchers should also expand the follow up examination of IPE to include both academic and clinical (e.g., Coiro, Kotchick, \& Preis, 2016; Miolo \& DeVore, 2016) educational experiences.

\section{Conclusions and Recommendations for Educators}

The current study also provides information for educators related to students' recommendations for future IPE activities similar to the IPE Stroke Workshop. It is evident from the suggestions, such as increased family participation and add more patients, that students value the patient interaction aspect of the workshop. Additionally, students consistently requested more time to discuss aspects of the patient within their small interprofessional groups. Despite the differences in IPE activities (academic versus clinical placement), Reeves and Freeth's (2002) follow up study provided similar suggestions related to students wanting longer time with other disciplines to deepen their understanding and students requesting greater preparation prior to the IPE experience.

The committee charged with developing the workshop has made changes based on this feedback and other feedback from the students. First, the workshop now includes three patients with different etiologies and diagnoses to provide the students who attend different nights of the workshop a varied experience. The additional patients include a young woman with a developmental delay and a seizure disorder, and a college athlete diagnosed with cancer. Second, the committee reduced the size of the small, interprofessional groups to 10 to 12 students instead of 15. Finally, the committee developed and provided students with preparation materials including worksheets with information about the educational background about each discipline, clearer instructions for the plan of care, and a worksheet for each discipline to practice stating their role in stroke care prior to the workshop. The committee will continue to look for methods to modify the workshop to maximize student learning.

Overall, most SLP students described that IPE Stroke Workshop had a positive effect on their clinical experiences one year after the workshop. Students perceived this workshop as an ideal venue for achieving learning outcomes related to the IPE Competency Domains.

\section{References}

Barnes, D., Carpenter, J., \& Dickinson, C. (2000). Interprofessional education for community mental health: Attitudes to community care and professional stereotypes. Journal of Social Work Education, 19, 565-583. 
Coiro, M. J., Kotchick, B. A., \& Preis, J. (2016). Youth social skills groups: A training platform for promoting graduate clinician interprofessional competence. Journal of Interprofessional Education \& Practice, 4, 89-92.

Copley, J. A., Allison, H. D., Hill, A. E., Moran, M. C., Tait, J. A., \& Day, T. (2007). Making interprofessional education real: A university clinic model. Australian Health Review, 31(3), 351-357.

Council on Academic Accreditation (2016). 2017 Standards for accreditation. Retrieved from http://caa.asha.org/reporting/standards/2017-standards/.

Creswell, J. W. (2013). Research design: Qualitative, quantitative, and mixed methods approaches. London: Sage Publications.

DiVall, M. V., Kolbig, L., Carney, M., Kirwin, J., Letzeiser, C., \& Mohammed, S. (2014). Interprofessional socialization as a way to introduce collaborative competencies to first-year health science students. Journal of Interprofessional Care, 28(6), 576-578.

Edwards, C. M., Newell, J. M., Rich, D. W., \& Hitchcock, L. I. (2015). Teaching Interprofessional Practice: An exploratory course assignment in social work and speech-language pathology. Journal of Teaching in Social Work, 35(5), 529-543.

Evans, J. L., Henderson, A., \& Johnson, N. W. (2012). Interprofessional learning enhances knowledge of roles but is less able to shift attitudes: A case study from dental education. European Journal of Dental Education, 16, 239-245.

Hylin, U., Nyholm, H., Mattiasson, A. C., \& Ponzer, S. (2007). Interprofessional training in clinical practice on a training ward for healthcare students: A two-year follow-up. Journal of Interprofessional Care, 21, 277-288.

Interprofessional Education Collaborative Panel. (2011). Core competencies for interprofessional collaborative practice: Report of an expert panel. Washington D.C.

Kent, F., Drysdale, P., Martin, N., \& Keating, J. L. (2014). The mixed-discipline aged-care student clinic: An authentic interprofessional learning initiative. Journal of Allied Health, 43(1), 51-56.

Moustakas, C. (1994). Phenomenological research methods. London: Sage Publications.

Merriam, S. B. (2009). Qualitative research: A guide to design and implementation. San Francisco, CA: Jossey-Bass.

Miolo, G., \& DeVore, S. (2016). Speech language pathology and education students engage in interprofessional collaborative practice to support children with special needs in preschool settings. Journal of Interprofessional Education \& Practice, 4, 81-87.

Neville, C. C., Petro, R., Mitchell, G. K., \& Brady, S. (2013). Team decision making: design, implementation and evaluation of an interprofessional 
education activity for undergraduate health science students. Journal of Interprofessional Care, 27, 523-525.

Nisbet, G., Hendry, G. D., Rolls, G., \& Field, M. J. (2008). Interprofessional learning for pre-qualification health care students: An outcomes-based evaluation. Journal of Interprofessional Care, 22(1), 57-68.

Pechak, C., Gonzalez, E., Summers, C., \& Capshaw, S. (2013). Interprofessional education: a pilot study of rehabilitation sciences students participating in interdisciplinary international service-learning. Journal of Allied Health, 42(3), 61E-66E.

Reeves, S., \& Freeth, D. (2002). The London training ward: An innovative interprofessional learning initiative. Journal of Interprofessional Care, 16, 41-52.

Reeves, S., Zwarenstein, M., Goldman, J., Barr, H., Freeth, D., Koppel, I., \& Hammick, M. (2010). The effectiveness of interprofessional education: Key findings from a new systematic review. Journal of Interprofessional Care, 24, 230-241.

van Soeren, M., Devlin-Cop, S., MacMillan, K., Baker, L., Egan-Lee, E., \& Reeves, S. (2011). Simulated interprofessional education: An analysis of teaching and learning processes. Journal of Interprofessional Care, 25(6), 434-440.

Wallace, S.E., Turocy, P.S., DiBartola, L.M., DeIuliis, E.D., Weideman, Y., Morgan, A., Astle, J., Cousino, S., O’Neil, C., \& Simko, L.C. (2016). Interprofessional education outcome study: Learning and understanding professional roles in stroke care. Journal of Physical Therapy Education, $30,50-60$.

World Health Organization. Framework for action on interprofessional education \& collaborative practice. Geneva: World Health Organization 2010. Retrieved from http://whqlibdoc.who.int/hq/2010/WHO_HRH_HPN_10.3_eng.pdf.

Zhao, D., Nagarajan, S., \& Nisbet, G. (2015). Informal learning opportunities matter: The Interprofessional learning experiences of undergraduate speech pathology students. International Journal of Practice-based Learning in Health and Social Care, 3(2), 17-31. 


\section{Appendix \\ Questionnaire}

The following questions relate to your clinical experiences during or after the time of the IPE Stroke Workshop.

1. Since the Workshop how many clinical placements have you completed (including any you were participating in during the time of the workshop)?

2. How many of your clinical placements include the following settings (place a number next to the setting)?

University-based Outpatient Clinic

Outpatient Medical Adults

Outpatient Pediatrics

Inpatient Adults

Inpatient Pediatrics

Skilled Nursing Facility

School (non-specialty)

Specialty School

Other, Describe:

Provide any detailed information that would be helpful in understanding the setting of your clinical placement.

3. On average, how many hours/week have you been involved in providing clinical services in each of these clinical settings? (Write the number of hours next to each setting).

University-based Outpatient Clinic

Outpatient Medical Adults

Outpatient Pediatrics 
Inpatient Adults

Inpatient Pediatrics

Skilled Nursing Facility

School (non-specialty)

Specialty School

Other, Describe:

4. Which populations did you primarily serve in your clinical placements?

Elderly Adults

Adults

Children

Infants

5. On average, how many hours/week have you been involved in providing clinical services (at any of your placements) to each of these populations? (place a number of hours next to the population).

Elderly Adults

Adults

Children

Infants

6. How many hours since the IPE Stroke Workshop have you spent providing clinical services to individuals with stroke?___ (approximately). Approximately what percentage of your clinical experiences since the Workshop have been with people who had stroke?

7. Describe how you believe the workshop affected your view of other healthcare professions. Either specific or general comments are welcome.

8. Reflecting back the Workshop - you completed preparatory activities, you met a patient and his family, developed patient questions within small interprofessional groups, asked patient questions and listened to answers to other students' questions, 
developed a patient plan of care, and reflected on the workshop experience in a large group.

a. Which 3 elements of the workshop were most valuable for your future clinical experiences? (highlight your responses)

1. preparatory activities

2. meeting a patient and his family

3. developing patient questions within small interprofessional groups

4. asking patient questions and listening to answers to other students' questions

5. developing a patient plan of care within small interprofessional groups

6. reflecting on the workshop experience in a large group

b. Which 3 elements of the workshop were least valuable for your future clinical experiences?

1. preparatory activities

2. meeting a patient and his family

3. developing patient questions within small interprofessional groups

4. asking patient questions and listening to answers to other students' questions

5. developing a patient plan of care within small interprofessional groups

6. reflecting on the workshop experience in a large group

9. What would you change about the workshop for future years? (List three things).

1.

2.

3. 
10. Interprofessional education seeks to address these four areas of learning:

- Values \& Ethics for Interprofessional Practice

- Roles \& Responsibilities

- Interprofessional Communication

- Teams and Teamwork

a. Which of these is most important for your future clinical practice? Why?

b. Which of these is least important for your future clinical practice? Why?

c. Which of these do you believe were addressed in the IPE Workshop?

d. Which of these do you believe are addressed in your discipline-specific curriculum (aside from the IPE Workshop)? Describe where and when (which courses?).

e. Which of these do you believe are not addressed in your discipline-specific curriculum?

11. What was the single most valuable aspect of the workshop?

12. Please provide any other comments. 